\title{
METRÓPOLE SUSTENTÁVEL? Não é uma questão urbana
}

\author{
Yoshiya Nakagawara Ferreira \\ Professora de Pós-Graduação em Meio Ambiente e Desenvolvimento da Universidade Estadual de Londrina
}

\begin{abstract}
Resumo: As raízes culturais e o processo capitalista no mundo contemporâneo desenharam a atual configuração socioespacial. A degradação da qualidade ambiental exige novas posturas éticas, fundadas em uma ética do futuro. O atual quadro da problemática ambiental deve ser pensado, assim, na relação com a condição cultural e o desenvolvimento sustentável.

Palavras-chave: metrópole; meio ambiente; cultura e ética; sustentabilidade; educação ambiental.
\end{abstract}

A vida humana na face da terra tem sido transgredida em todos os níveis e formas, desde as últimas décadas do século XX. As aceleradas transformações socioeconômicas e culturais, que afetam nosso planeta, têm rompido com todos os padrões e comportamentos éticos. A perplexidade constante tem dificultado até a compreensão das contradições e fenômenos nunca antes imaginados. O desdobramento dessas mudanças ocorre em todos os níveis e para quase todos os habitantes da terra, indistintamente.

O homem metropolitano, premido pelo exíguo e poluído espaço, que sempre é dos outros, pelo limitado tempo que é obrigado a viver, pelo sonho que não é mais colorido, pela velocidade dos acontecimentos e pela irreversibilidade sentida e vivida no cotidiano, certamente, se sente mais impotente, mais amargo e menos criativo.

Entender uma metrópole brasileira pode guardar algumas semelhanças com as metrópoles latino-americanas, porém, as identificações com as metrópoles norte-americanas, européias ou japonesas tomam outra dimensão, assim como os desdobramentos socioespaciais guardam diferentes relações, principalmente no que se refere às formas de uso do solo, à composição e renda da população e às infra-estruturas coletivas disponíveis para a população. Certamente, decifrar ou entender a metrópole brasileira contemporânea não é a mesma coisa que compreender uma metrópole em um outro contexto sociopolítico. Um outro fator que pode influir diz respeito à questão da gênese, evolução e processo migratório para as regiões metropolitanas. No caso latino-americano, embora dentro do mesmo processo capitalista do sistema-mundo, a importância das transformações do mundo agrário (Brumer e Santos, 1997; Martine, 1987; Nakagawara, 1981) assume um papel fundamental na análise do viver metropolitano.

A atual crise da macroestrutura tem influências poderosas tanto a nível territorial como em termos social, político ou cultural. Assim, a crise do capitalismo hoje possui desdobramentos territoriais em vários níveis, que se refletem em todos os setores de atividade e no cotidiano das pessoas. Historicamente, há vários exemplos que podem ser citados, como a crise religiosa do renascimento, que implicou uma crise dos valores morais e estéticos, significando uma ruptura essencial com a visão de mundo humanista-renascentista. ${ }^{1}$

No território brasileiro, ocorreram grandes transformações agrícolas e agrárias nas décadas de 60 e 70 que afetaram a relação entre uso e posse da terra. A "modernização agrícola", favorecendo as culturas destinadas à exportação e às agroindústrias, como trigo, soja, cana-deaçúcar e milho, estimulou a concentração fundiária e o aumento na utilização de maquinários agrícolas, influindo fortemente nas relações de trabalho. Quase 30 milhões de pessoas deixaram o campo entre 1960 e 1980, acelerando o processo de urbanização e "inchando" metrópo- 
les e cidades de tamanho médio entre 100 a 500 mil habitantes. ${ }^{2}$

Entretanto, a geração de empregos nas cidades, tanto nas indústrias como nos setores de serviços, foi insuficiente para absorver essa massa demográfica, mais a população ativa que crescia sempre de forma avassaladora. Sendo a metrópole uma grande receptora, pode-se supor a desordem crescente que se estabelece, não só pela dificuldade do poder público no acompanhamento do crescimento das periferias, mas principalmente pela complexidade relacionada aos alojamentos e condições de trabalho, no processo de excludência social cada vez mais expressivo no mundo capitalista. A dita "modernização agrícola" tem o seu reverso na "modernização conservadora", expressão já consagrada nas análises sociais e econômicas. No ambiente urbano, o mundo rural e o mundo urbano convivem lado a lado, superpondo-se, anulando-se, complementando-se, criando urgências nunca entendidas pelos administradores públicos, e o homem recém-migrado vai perdendo a sua identidade, agora, membro cada vez mais temporário do locus urbano. O lugar, tão importante para a experiência humana, torna-se apenas uma estratégia para viver o hoje, nunca o amanhã. ${ }^{3}$

Estabelecem-se, assim, na natureza estrutural dos conflitos urbanos, mais conflitos sociais, com grandes dimensões espaciais. $\mathrm{O}$ agigantamento das metrópoles passa a interessar aos estudiosos e aos governantes. Como entendêla? Como ordená-la?

Nas academias e nas instituições públicas ou privadas muito se tem escrito sobre as metrópoles, assim como exercícios de elocubrações estatísticas também recheiam a historiografia metropolitana. O homem metropolitano, este ser manipulável e manipulado pelo processo capitalista e pelas circunstâncias determinadas historicamente, segue o seu estreito caminho sem ter tempo de refletir qual é o melhor rumo.

Este artigo, não traz nenhum embate teórico ou metodológico, pois são sempre muitas as contribuições nesse sentido, principalmente na temática urbana. Entretanto, aliando-se à consciência ético-ambiental iniciada a partir da ameaça de hecatombe nuclear global, pretende-se fazer aqui uma abordagem mais cultural.

Hoje, são sentidos os efeitos trágicos dos agrotóxicos, da perda da biodiversidade, da extinção das espécies, da degradação ambiental e da perda da qualidade de vida. Estamos em crise permanente. Nas metrópoles, já não se permite pensar em descansar em uma praça, nem durante o dia. Nos ônibus e metrôs, há o risco de agressões, assal- tos e medo permanente. As crianças não podem mais brincar nas ruas, os adultos não têm nem o direito de sonhar com um bom trabalho e os velhos não possuem mais espaço nas urbi. Afinal, são velhos... Somos uma civilização do lixo - do doméstico ao atômico. Há 50 anos, seria uma ficção hilariante pensar que o homem não saberia como se desfazer do lixo produzido por ele mesmo. Colocá-lo no navio, qual fantasma errando pelo mundo, sem lugar para o seu destino, entre outras "curiosidades" absurdas.

Desejamos isso? Buscamos isso?

Além dos absurdos - e é preciso que se diga, que se escreva, porque o homem está ficando cada vez mais surdo, mais indiferente ao seu próximo -, tem-se uma crise/ mudança que se avoluma hoje: a dos grandes sistemas explicativos (científicos e filosóficos) de mundo, englobando crise do "capitalismo" (a crise socioambiental é a maior crise do que se pode chamar de "capitalismo" e põe o modelo econômico atual em xeque), crise das relações humanas dentro do mundo do trabalho e no mercado, da família patriarcal, das culturas locais diante da globalização, dos ideários comunistas, de todos os ramos de conhecimento, crise de identidade, crise da velocidade e fragmentação das redes de linguagem e discursos (Pelizzoli, 1999:94-ss.).

Problemas ambientais, hoje, são nossos problemas socioambientais. Fatalmente, onde quer que o homem esteja, numa aldeia montanhosa, longe da civilização, ou "espremido" nos trens dos subúrbios, todos serão mais ou menos afetados. Para o filósofo e ecólogo Pelizzoli (1999), o conceito-chave para a superação está no desenvolvimento sustentável. Este conceito deve ser levado às últimas conseqüências. Além disso, "o novo modelo desejado só se efetivaria quando do revolvimento e reversão de toda uma estrutura institucional política e pública, empresarial, estilos de socialização obsoletos, e na base de uma ética, a florescer dentro de um processo de reestruturação socioeconômica mais equilibrado e justo, permeado sempre pelo caráter da educação (ambiental) para a cidadania". Essa seria a ética do futuro: trabalhar pensando no "sujeitocomunidade" (Pelizzoli, 1999:98).

Que ética permeou-nos até aqui?

Uma ética antropocêntrica (Pelizzoli, 1999:138), que é legitimadora de um contrato social excludente - homem $\mathrm{x}$ homem, todos os homens $\mathrm{x}$ natureza. Nesta ética - a educação centrou-se no habitus e potencialização desses valores - têm-se como pano de fundo a autonomia e o poder de um pseudo-sujeito evadido do seu ambiente - origina- 
dos num escopo individualizado, não-integrado, que se mescla a uma prática de conhecimento objetivo. Em poucas palavras, o homem estaria construindo a sua emancipação às custas da depleção da natureza e do outro.

$\mathrm{Na}$ análise de Hans Jonas (apud Giacóia Júnior, 2000:197), nas características tradicionas, "Ética tinha a ver com o aqui e agora, com ocasiões, tais como se estabelecem entre os homens, com as típicas situações recorrentes da vida privada e pública. $\mathrm{O}$ homem bom era aquele que enfrentava essas ocasiões com virtude e sabedoria, que cultuava em si mesmo a capacidade para tanto e se conformava com o desconhecido.

As novas dimensões da responsabilidade terão que ser fundamentadas em outras bases. Nessa perspectiva, a ética do futuro, proposta por Pelizzoli, fundamenta-se numa "virada ética e ecológica, que deve estar na base de toda discussão ambiental e da produção de conhecimento e pesquisa sérios. Esta é uma guinada teórica que advoga um caráter integrador e mais biocêntrico, que põe os valores da manutenção da vida e a integridade humana planetária na base da questão" (Pelizzoli, 1999:97-ss.).

Por que é difícil essa tarefa? Talvez porque a noção de antiambiental (Grun apud Pelizzoli, 1999:141-ss.) recheia o nosso cotidiano com ideais e pressupostos que permearam a educação convencional, conforme exemplos sintéticos:

- tornar-se humano é distinguir-se o mais possível da natureza - enquanto esta é selvagem -, do primitivo;

- dominar a natureza exterior para, através disso, libertar-se a si mesmo;

- sistematizar todo o saber, já positivamente abrangente, na forma enciclopédica, colocando-o à mão do pesquisador;

- predominância excessiva da temática metodológica em detrimento ao sentido e contextos;

- inquirir a natureza, obrigando-nos a dar respostas (como em Bacon);

- "código curricular" cienticista, reducionista e deslocado; expulsão de tudo o que não é "científico";

- pragmatismo, individualismo e competição exacerbados;

- educação - questão apenas entre o indivíduo e a aprendizagem, instrumentalizar;

- afirmação da objetividade do conhecimento implicando reducionismo;

- modelo explicativo de mundo - causal-mecânico e químico-matemático;
- recalque dos saberes locais, sabedorias, tradições; afã pelo novo tecnológico e deprezo pelo antigo. História como presente puro;

- educação objetificadora - legitimação do paradigma industrialista do capitalismo;

- educação - mão-de-obra para o mercado. Defesa das condições de produção e reprodução da lógica do capital;

- educação - desenvolver a essência "humana" em suas potencialidades, mas com uma concepção problemática do que seja o "humano". Ideal: autonomia individual, mas dentro da ordem vigente;

- história como mera historiografia, sem dinâmica e imbricação contextual e política.

Uma outra vertente que importante e fundamental para tentar reverter o atual quadro geral da problemática ambiental poderia estar embasada na nossa condição cultural. Mesmo a questão do desenvolvimento sustentável, que seria um dos caminhos para a superação de muitos problemas hoje enfrentados, se assenta no nosso comportamento cultural.

Não há necessidade de apresentar aqui as discussões sobre o que se entende por cultura, o que fugiria do objetivo deste artigo, mas são abordados alguns conceitos mais difundidos.

Um dos teóricos da área, Ortiz (1997), argumenta que cultura e espaço encontravam-se intimamente articulados a um território fisicamente demarcado, e cada cultura possuiria fronteiras que lhes são próprias, embora a sua dimensão pudesse variar. Entretanto, segundo o autor, a globalização das sociedades e a mundialização da cultura rompem com essa integridade espacial, tornando cada vez mais difícil discernir os limites de cada povo ou cultura. Assim, a mundialização da cultura traz em seu bojo uma territorialidade que não mais se vincula ao entorno físico.

Sachs (2000), um especialista em problemas ambientais, coloca a cultura como mediadora entre a sociedade e a natureza. Cultura, segundo suas palavras, é um conjunto de valores, dos usos e das instituições, profundamente ligado a postulados éticos. Por outro lado, também está articulado com uma outra variável extremamente importante neste jogo de harmonização do social, do ecológico e do econômico, que é o estilo de vida.

Um outro estudioso da cultura, Featherstone (1997), registra que "existe uma crise cultural", sendo necessário um "diagnóstico do nosso tempo", pois o processo de globalização não produziu a uniformidade cultural; ao contrário, nos tornou mais conscientes de novos níveis de 
diversidade e das muitas facetas da cultura. O autor adverte que o processo de globalização nem sempre leva as pessoas a uma sensibilidade maior quanto às diferenças culturais. Ele assinala a existência de uma cultura global: um conjunto de práticas, conhecimentos, convenções e estilos de vida que se desenvolveram de modo a se tornar cada vez mais independentes dos Estados-Nação.

No relatório sobre cultura e desenvolvimento organizado por uma comissão mundial da Unesco (Cuéllar, 1997), há uma síntese sobre o conceito de desenvolvimento relacionado à cultura: o desenvolvimento divorciado de seu contexto humano e cultural não é mais do que um crescimento sem alma. O desenvolvimento econômico, em sua plena realização, constitui parte da cultura de um povo. Essa idéia, contudo, não é comumente aceita. A visão convencional trata a cultura como fator catalisador ou como obstáculo ao desenvolvimento econômico, o que conduz à necessidade de levar "em consideração os fatores culturais do desenvolvimento". Todavia, a tese contida nesse relatório é a de que o desenvolvimento compreende não apenas o acesso a bens e serviços, mas também a possibilidade de escolher um estilo de coexistência satisfatório, pleno e agradável, ou seja, o desabrochar da existência humana em suas várias formas.

O propósito desse relatório foi mostrar como a cultura forja todo nosso pensamento, nossa imaginação e nosso comportamento. Ela é, ao mesmo tempo, o veículo da transmissão do comportamento social e uma fonte dinâmica de transformação, de criatividade, de liberdade e do despertar de oportunidades de inovação. Para grupos, tanto quanto para sociedades, cultura representa energia, inspiração, autonomia e capacitação, conhecimento e consciência da diversidade. Se a diversidade cultural está "atrás de nós, ao nosso redor e à nossa frente", como afirma Claude LéviStrauss, deve-se aprender a conduzi-la não ao conflito de culturas, mas à coexistência frutífera e à harmonia intelectual.

Conforme a síntese do relatório, tem-se um longo caminho pela frente. Ainda não aprendemos a respeitar plenamente o outro, a partilhar e a trabalhar em conjunto. Vivemos um período verdadeiramente excepcional da história, em que existem soluções também excepcionais. $\mathrm{O}$ mundo, tal como o conhecemos, com todos os seus relacionamentos e interações que tomamos como certos, está passando por profunda reavaliação e reconstrução. São necessárias, nesse contexto, a imaginação, a inovação, a visão ampla e a criatividade. Novas parcerias internacionais e formas de interação constituem um ingrediente es- sencial para a criatividade na solução dos problemas. Trata-se de uma qualidade que requer a disposição de lidar abertamente com questões difíceis, em vez de se ater a soluções convencionais. Isso exige mente e coração abertos, prontidão em buscar novas definições, capacidade de conciliar antigas oposições e de formular mentalmente novos tipos de mapas. Em última instância, será uma atitude honesta de introspecção que conduzirá à compreensão da experiência do outro, o que levará a um futuro no qual a busca da liberdade individual estará ligada de forma harmônica à necessidade de bem-estar coletivo, no qual nossas prioridades incluirão a empatia e o respeito pelo largo espectro das diferenças humanas.

O antropólogo Laraia (1999) faz um histórico referente ao desenvolvimento do conceito de cultura, a partir das manifestações iluministas até os autores modernos e demonstra como a cultura influencia o comportamento local e diversifica a humanidade.

$\mathrm{Na}$ premissa de que a ética e a formação cultural influem na conformação ambiental, modificando as relações socioespaciais, é necessário que se acredite na possibilidade de um desenvolvimento sustentável e, como Santos (2000) registrou: "não disparem sobre o utopista".

É importante ter em mente os principais conceitos já sistematizados e difundidos sobre desenvolvimento sustentável. No relatório da Comissão Mundial de Cultura e Desenvolvimento (Cuéllar, 1997), há conceitos amplos e alguns específicos sobre o desenvolvimento sustentável, aqui resumidos.

O desenvolvimento sustentável passou a significar muito mais do que a conservação intacta do capital físico que produz um fluxo de renda. A conservação, a substituição e o crescimento do volume de capital, tanto físico quanto humano, constituem, sem dúvida, um aspecto da sustentabilidade. $\mathrm{O}$ desgaste físico, a obsolescência técnica e a depreciação do capital humano têm de ser considerados.

Em segundo lugar, o capital físico - e não somente o humano - tem de ser conservado. O conhecimento técnico, gerencial e administrativo, e sua disseminação por meio da educação podem substituir o capital físico e ambiental - ou servir-lhe de complemento. A esperança da sustentabilidade repousa sobre a capacidade de inovação e a criatividade humanas, que substituem recursos não-renováveis por outros artificiais.

Um terceiro aspecto é a conservação das condições ambientais para a composição do bem-estar. Os resultados - e não os meios - devem ser sustentados, a não ser que os recursos ambientais que servem como matéria-pri- 
ma sejam valorizados por si próprios, como a floresta tropical amazônica, o Parque Nacional Tassili Najjer, na Argélia, os Meteora, na Grécia, ou o Parque Nacional Yosemite, nos Estados Unidos. Isso tem duas implicações distintas: primeiro, evitar a poluição das águas, do ar e da terra, dos quais dependem nossas vidas e nosso trabalho; segundo, evitar a exaustão dos recursos renováveis, essenciais à produção, enquanto uma substituição adequada não está disponível. Isso pode significar o aumento desses recursos ambientais, o que depende, mais uma vez, do crescimento populacional, da tecnologia, das preferências, e assim por diante. Da mesma forma que ocorre com os recursos não-renováveis, deve-se investir em produtos de substituição, visando conservar a base produtiva para a sustentação do bem-estar.

Existe ainda um aspecto da sustentabilidade: $a$ adaptabilidade. O sistema deve ser capaz de se ajustar aos choques e às crises, de ser suficientemente flexível e diversificado em relação aos recursos (incluindo a diversidade biológica) e às práticas (incluindo as perspectivas de conhecimento), a fim de se preservar das incertezas do futuro.

O quinto aspecto consiste em evitar a oneração das gerações futuras com dívidas internas e externas. Embora para todo o passivo de um devedor corresponda o ativo equivalente de um credor, isso não significa que o ônus líquido da dívida seja zero. O peso dos impostos e os juros auferidos têm efeitos importantes sobre o incentivo ao trabalho e a propensão a poupar e a assumir riscos, sem falar do impacto distributivo.

O sexto aspecto do desenvolvimento sustentável é a sustentabilidade fiscal, administrativa e política. Uma política deve ser crível e aceitável para os cidadãos, de forma a obter consentimento suficiente para sua implementação. $\mathrm{O}$ aparato administrativo deve estar apto a conduzir as reformas de modo continuado, com renda disponível para enfrentar as necessidades dos dispêndios públicos. A paz internacional e a segurança local constituem dimensões importantes da sustentabilidade.

Um sétimo aspecto é a capacidade de habilitar os cidadãos dos países em desenvolvimento para a condução de projetos, permitindo a retirada de especialistas estrangeiros sem que o sucesso das atividades seja afetado. Isso implica o treinamento de agentes locais e o apoio à criação de capacidade tecnológica, empresarial e administrativa local.

Por último, há um aspecto cultural pouco enfatizado, mas muito importante. Segundo o Relatório, é um equívoco tratar a cultura meramente como um instrumento da sustentação de alguma outra coisa, tal como o desenvolvimento econômico, ou como se ela fosse algo estático. Sublinham-se o seu papel constitutivo e a sua importância como objetivo em si, o que engloba o próprio desenvolvimento. Em ambos os aspectos, as avaliações e as atividades culturais podem ser vistas em termos de sustentabilidade cultural. Os componentes de valor de qualquer cultura em mutação não devem ser afetados por demandas conflitantes.

A sustentabilidade é, portanto, um problema multidimensional, que exige um comportamento responsável para com as gerações futuras - mas não a expensas das gerações contemporâneas -, apesar do fato de que aquelas gerações não votam nem podem exercer pressões sobre os formuladores de políticas.

A noção de sustentabilidade levanta, portanto, a questão de como a própria natureza é concebida - e, conseqüentemente, dos valores culturais que condicionam o relacionamento da sociedade com a natureza. Neste particular, o raciocínio anteriormente desenvolvido sobre ética e cultura pode indicar alguns rumos ou alternativas.

Não há conclusão a ser apresentada, apenas a sensibilização que se pretendeu colocar em palavras e, invocando a responsabilidade inadiável e irrevogável do papel do educador, a conscientização da quase barbárie social e ambiental do mundo contemporâneo, sem pensar nas gerações futuras. Porém, emprestando o termo de Pelizzoli (1999), "não sejamos os profetas da desesperança que não fazem mais do que legitimar o desespero, aumentar o pânico narcísico, e valerem-se hipocritamente da situação".

\section{NOTAS}

E-mail da autora: yoshiya@1dnet.com.br

1. Falcon (2000) faz uma análise aprofundada do assunto, tendo por hipótese que a natureza da crise residia, principalmente, na profunda oposição, já então evidente, entre duas visões de mundo na vida social, intelectual e mental da época, com suas respectivas posturas sociais distintas: uma, cristã, ou católico-feudal; a outra, humanista-renascentista, ou moderna, isto é, uma visão de mundo essencialmente providencialista e transcendente, em face de outra que, ao menos tendencialmente, se movia no sentido da imanência e afirmava uma atitude voluntarista por excelência.

2. Há inúmeras contribuições de economistas, geógrafos e sociólogos que já analisaram essa temática em publicações largamente difundidas, dispensando-se citações maçantes.

3. A leitura da obra de Castells (1999) dá a dimensão da complexidade.

\section{REFERÊNCIAS BIBIOGRÁFICAS}

BRUMER, A. e SANTOS, J.V.T. dos. "Tensões agrícolas e agrárias na transição democrática brasileira”. São Paulo em Perspectiva. São Paulo, Fundação Seade. v.11, n.2, abr.-jun. 1997. 
CASTELLS, M. O poder da identidade. (A era da informação: economia, sociedade e cultura; v.2). São Paulo, Paz e Terra, 1999 (Tradução Klauss Brandini Gerhardt).

CUÉLlAR, J.P. (org.). "Nossa diversidade criadora". Relatório da Comissão Mundial de Cultura e Desenvolvimento. Campinas, Papirus/Brasília, Unesco, 1997.

FALCON, F.J.C. "A crise dos valores morais, religiosos e artísticos". In: RODRIGUES, A.E.M. e FALCON, F.J.C. (orgs.). Tempos Modernos - ensaios de história cultural. Rio de Janeiro, Civilização Brasileira, 2000.

FEATHERSTONE, M. O desmanche da cultura: globalização, pós-modernismo e identidade. São Paulo, Studio Nobel/Sesc, 1997 (Tradução Carlos Eugênio M. de Moura).

GIACÓIA JR., O. "Hans Jonas: o princípio responsabilidade - Ensaio de uma ética para a civilização tecnológica”. In: OLIVEIRA, M.A. (org.). Correntes fundamentais da ética contemporânea. Petrópolis, Vozes, 2000.
LARAIA, R. de B. Cultura: um conceito antropológico. 12 a ed. Rio de Janeiro, Zahar, 1999.

MARTINE, G. "Efeitos esperados e imprevistos da modernização agrícola no Brasil”. In: MARTINE, G. e GARCIA, R.C. (orgs.). Os impactos sociais da modernização agrícola. São Paulo, Caetés, 1987.

NAKAGAWARA, Y. "Questões agrárias e urbanas - o caso norte-paranaense". Revista Terra e Cultura. Londrina, Cesulon, v.1, n.1, 1981, p.94-115.

ORTIZ, R. "Mundialização, cultura e política". In: DOWBOR, L. et alii (orgs.). Desafios da globalização. 2a ed. Petrópolis, Vozes, 1997.

PELIZZOLI, M.L. A emergência do paradigma ecológico: reflexões ético-filosóficas para o século XXI. Petrópolis, Vozes, 1999.

SACHS, I. "Sociedade, cultura e meio ambiente". Mundo \& Vida-Alternativas em estudos ambientais. Niterói, ano I, v.I, 2000, p.7-13.

SANTOS, B. de S. Para um novo senso comum: a ciência, o direito e a política na transição paradigmática. São Paulo, Cortez, v.1, 2000. 